\title{
BIAXIAL FLEXURAL STRENGTH OF UN-SHADED AND SHADED MONOLITHIC TRANSLUCENT ZIRCONIA
}

\author{
Maher R. Mohamed ${ }^{1 M s c}$, Sanaa H. Abdel Kader ${ }^{2 h n}$, Yehia H. Aboushady ${ }^{3 p h}$, \\ Mona M. Abd El-latif ${ }^{4 h h}$
}

\begin{abstract}
INTRODUCTION: The natural white color of zirconia together with the veneer chipping problem has led to the development of tooth colored monolithic (full-anatomic) zirconia. In order to optimize esthetics shading of monolithic zirconia were done by two main approaches, either by powder mixing method or by infiltration technique. The influence of infiltration technique on mechanical properties of zirconia has been reviewed previously, while the influence of powder mixing method on the mechanical properties of shaded zirconia, specially the biaxial flexural strength has not been widely studied before.

OBJECTIVES: To evaluate and compare the biaxial flexural strength and the crystal structure of shaded CAD/CAM monolithic translucent zirconia by powder mixing method with un-shaded ones.

MATERIALS AND METHODS: Twenty fully sintered discs of un-shaded [T 0] and shaded [T S] monolithic translucent zirconia of diameter $12 \mathrm{~mm}$ and thickness $1 \mathrm{~mm}$ has been divided into 2 parallel groups of 10 discs each. Their biaxial flexural strength was measured using a ball-on-ring test fixture and universal testing machine at room temperature. Statistical significance was measured using One-Way ANOVA test. Then crystallographic analysis was done for both groups using X-ray diffraction. Finally the nature of failures of the tested specimens was examined using confocal laser microscopy.

RESULTS: Biaxial flexural strength test showed no significant difference between un-shaded and shaded specimens. X-ray diffraction spectrum only showed crystals of tetragonal zirconia with no evidence of neither monoclinic zirconia crystals nor coloring oxides crystal phases. Confocal laser microscopy images of both groups showed the classic fracture patterns of monolithic zirconia materials.

CONCLUSIONS: shading of zirconia blocks by powder mixing methods does not significantly ( $\mathrm{P} \geq 0.05)$ affect either biaxial flexural strength or crystallographic structure of monolithic translucent zirconia.

KEYWORDS: Monolithic; Zirconia; Shaded; Biaxial Flexural strength.

1. Instructor of Fixed Prosthodontics, Department of Conservative Dentistry, Faculty of Dentistry, Alexandria University, Alexandria, Egypt.

2. Professor of Fixed Prosthodontics, Department of Conservative Dentistry, Faculty of Dentistry, Alexandria University, Alexandria, Egypt.

3. Professor of Fixed Prosthodontics, Department of Conservative Dentistry, Faculty of Dentistry, Alexandria University, Alexandria, Egypt.

4. Professor of Fabrication Technology Research Department, Advanced Technology and New Materials Research Institute (ATNMRI), City of Scientific Research and Technological Applications, New Borg El-Arab City, Alexandria, Egypt.
\end{abstract}

\section{INTRODUCTION}

Since its introduction in dentistry, Zirconia has been widely used by dentists and dental technicians for allceramic fixed dental prosthesis implant abutments, endodontic posts, orthodontic brackets and implant fixtures (1-5). Several ceramic materials were proposed to create metal free all-ceramic restorations. However, their incomparable mechanical properties with zirconia limit their use especially when a posterior fixed partial denture is needed $(6,7)$.

Notwithstanding the superior mechanical properties of zirconia, the white color of 3 mole \% yttria-stabilized tetragonal dental zirconia (3Y-TZP) restraint its use in highly esthetic areas (8). And that's why zirconia restorations were first introduced in prosthetic dentistry as a core material and then layered by feldspathic porcelain. However, chipping, wear or fracture of the veneering porcelain was the main issues that faced layered zirconia restorations, and fracture of the core was never reported (9). The natural white color of 3Y-TZP together with the veneer chipping problem has led to the development of tooth colored monolithic (full-anatomic) zirconia without the need of veneering porcelain to obtain natural esthetics $(10,11)$

This superior mechanical properties of 3Y-TZP is attributed to its unique crystal phase transformation (Transformation toughening), in which tetragonal crystal phase which is metastable transform to the more stable monoclinic crystal phase upon application of mechanical stress. This transformation is accompanied by grain expansion generating compressive stresses to stop crack propagation (12-14). However, this metastable tetragonal phase could spontaneously transforms into the monoclinic phase in a humid atmosphere even without mechanical stress, which starts at the surface then enters the bulk of the material. This process is often named zirconia gaining or low-temperature degradation (LTD) (15). And this could be a problem with full anatomic monolithic zirconia as it is directly exposed to saliva and mechanical stresses in oral environment.

Shading or tooth-like color of zirconia can be done by incorporation of coloring metal oxides $(16,17)$. There are two main approaches for obtaining a shaded zirconia currently available for dental purposes; metal oxides can be mixed with the starting $\mathrm{ZrO} 2$ powder at the production stage to obtain shaded blocks (powder mixing method) or before or after sintering, frameworks can be infiltrated with specific coloring liquids using a brush (infiltration technique)(16-19). The influence of infiltration technique on mechanical properties of zirconia has been reviewed previously. In 2008, Hjerppe et al. showed that infiltration technique the effect of coloring pigments depends on its concentration, where specimens showed significant decrease in strength with high coloring liquids concentrations using ICE Zirkon ( Zirkonzahn, Sand in Taufers, Italy) (18) similar results were reported by other studies $(17,20)$. In contrast, Pittayachawan et.al reported 
that there wasn't significant difference in biaxial flexural strength between shaded and un-shaded zirconia using Lava system(3M/ESPE, St.Paul, USA) (21). Analyses of literature showed only few studies done on the effect of powder mixing method on mechanical properties of monolithic zirconia. Recently in 2016, Spyropoulou et.al studied using shaded and un-shaded Nobel Procera (Nobel Biocare $A B$ ) monolithic zirconia and reported that there were no significant difference in initial biaxial flexural strength( before fatigue cycling test) (22).

Based on the above, the main aim of this work was to study the effect of shading by powder mixing method on both biaxial flexural strength and crystallographic structure of translucent monolithic zirconia and we hypothesized that the shading of monolithic zirconia won't have negative effect on both properties.

\section{MATERIALS AND METHODS}

Twenty one male albino rats weighing about 200-250 grams

\section{Study design}

This study was parallel, controlled experimental study, in which biaxial flexural strength of two groups of Un-shaded (Zenostar Zr T 0) and Shaded (Zenostar Zr Ts) translucent monolithic zirconia were tested. Also Crystallographic and Fractorgraphic analysis of the two groups were done and compare.

\section{Specimens' preparation}

The data of the required specimens shape and dimensions were input in CAD/CAM system (Zenotec select hybrid system, Wieland Dental + Technology GmbH \& Co. KG, Pforzheim, Germany) using Stereolithography (STL) file format custom made with dimensions of the required disc (12 mm diameter and $1 \mathrm{~mm}$ thickness). Monolithic Unshaded T0 and Shaded TS translucent zirconia discs from Zenostar Zr (Wieland Dental, Pforzheim, Germany) (Table 1) were milled using CAD/CAM system to obtain 10 unshaded zirconia discs [control group] and 10 shaded zirconia discs [study group]. Then both groups were transferred to sintering furnace (Programat S1; Ivoclar Vivadent, Inc). In a batch of 5 , discs were sintered at $1500^{\circ} \mathrm{C}\left(2732^{\circ} \mathrm{F}\right)$ for 3 hours 45 minutes according to manufacture instruction. After that sintering discs were left to cool to room temperature and then inspected visually for any defects or cracks and over a black background to see the difference in color developed after sintering [Figure 1].

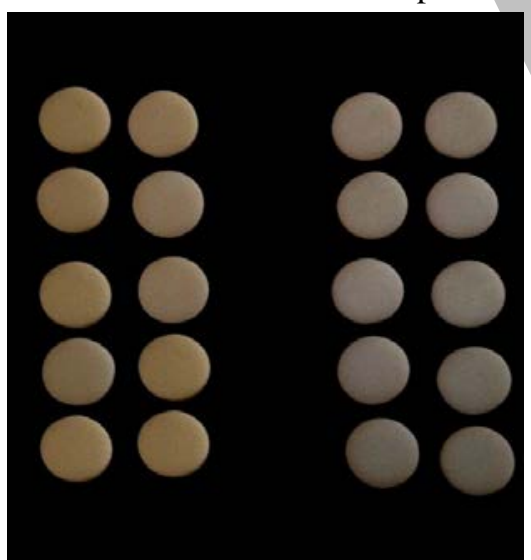

Figure 1: Shaded zirconia discs (left) and un-shaded zirconia discs (right) after sintering.
Table 1: Showing materials used in the study, their manufacturer, LOT number and chemical components

\begin{tabular}{|c|c|c|c|}
\hline $\begin{array}{l}\text { Monolithic } \\
\text { Zirconia }\end{array}$ & "Manufacturer & $\begin{array}{l}\text { Lot. } \\
\text { Number }\end{array}$ & $\begin{array}{l}\text { Chemical } \\
\text { Composition }\end{array}$ \\
\hline $\begin{array}{l}\text { Un-shaded } \\
\text { Zenostar } \\
\text { Zr T } 0\end{array}$ & $\begin{array}{l}\text { Wieland } \\
\text { Dental, } \\
\text { Pforzheim, } \\
\text { Germany }\end{array}$ & $\begin{array}{l}\text { T24107 } \\
\text { T24486 }\end{array}$ & $\begin{array}{l}\mathrm{ZrO}_{2}+\mathrm{HfO}_{2}+ \\
\mathrm{Y}_{2} \mathrm{O}_{3}>99 ; \\
4,5<\mathrm{Y}_{2} \mathrm{O}_{3} \leq 6 ; \\
\mathrm{HfO}_{2} \leq 5 ; \\
\mathrm{Al}_{2} \mathrm{O}_{3}+\text { other } \\
\text { oxides } \leq 1\end{array}$ \\
\hline $\begin{array}{l}\text { Shaded } \\
\text { Zenostar } \\
\text { Zr T S }\end{array}$ & $\begin{array}{l}\text { Wieland } \\
\text { Dental, } \\
\text { Pforzheim, } \\
\text { Germany }\end{array}$ & $\begin{array}{l}\text { T28424 } \\
\text { T28424 }\end{array}$ & $\begin{array}{l}\mathrm{ZrO}_{2}+\mathrm{HfO}_{2}+ \\
\mathrm{Y}_{2} \mathrm{O}_{3}>99 ; \\
4,5<\mathrm{Y}_{2} \mathrm{O}_{3} \leq 6 ; \\
\mathrm{HfO}_{2} \leq 5 ; \\
\mathrm{Al}_{2} \mathrm{O}_{3}+\text { other } \\
\text { oxides(including } \\
\text { coloring oxides } \\
\leq 1\end{array}$ \\
\hline
\end{tabular}

\section{Thermocycling (Aging) of zirconia}

The specimens were then subjected to 1200 thermal cycles corresponding to one year of clinical service, by mechanical transfer between $5^{\circ} \mathrm{C}$ and $55^{\circ} \mathrm{C}$ water baths with a dwell time of one minute in each bath and relaxation period of 30 seconds in air between the two baths using thermal cycling machine (Department of dental biomaterials, Alexandria University, Egypt) (23).

\section{Sample Preparation for Bi-axial flexural strength} (BFS) test

To provide a consistent flat loading surface the upper surfaces of all samples were wet ground on one side only with P400, P1000, P1200, P1500, P 2000 silicon carbide abrasives on a lapping machine (Department of dental biomaterials, Alexandria University, Egypt) at $150 \mathrm{rpm}$. Discs were then left to be cleaned in a sonicator bath [Kerry Ultrasonics, Guyson Int. LTD, UK] for 10 minutes. After that discs were stored to dry and tested at room temperature in an effort to eliminate the potential effects of water on the BFS test results.

\section{Bi-axial flexural strength test}

Using Universal Testing Machine [Maxitorq,Com-Ten industries,Florida,USA,] the biaxial flexural strength [BFS] of both groups was tested using a ball-on-ring test configuration. Ten discs from each group supported by a 10 -mm diameter knife-edge were centrally loaded via a 4 $\mathrm{mm}$ diameter spherical ball indenter at a crosshead speed of 1-mm/min until specimen failure [Figure 3].

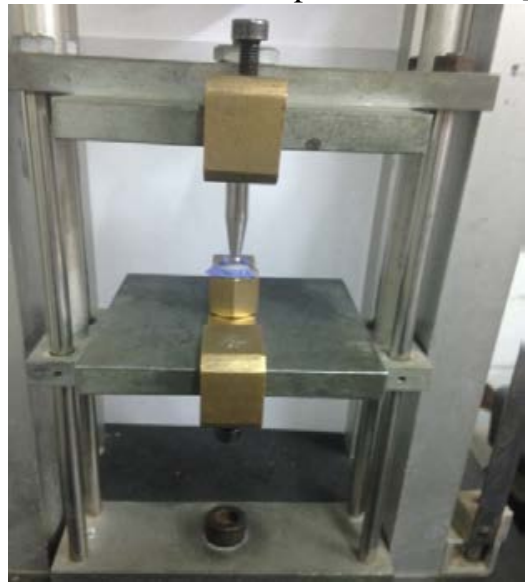

Figure 2: Biaxial flexural strength test set up. 
During testing, all the test specimens were placed with the grounded surface facing upward toward the indenter. To distribute the load evenly, a thin section of rubber was placed between the support and the disc (24). Diameter of each disc and the rubber sheet was measured using digital micrometer (Neiko, Zhejiang Kangle Group, China) and recorded before testing. The bi-axial flexural strength were calculated according to the following equation (25):

$\sigma \max =\mathrm{P} / \mathrm{h} 2\{(1+\mathrm{v})[0.485 \times \ln (\mathrm{a} / \mathrm{h})+0.53]+0.48\}$ $\sigma$ max is the maximum tensile stress, $P$ is the measured load at fracture, a is the radius of the knife-edge support, $\mathrm{V}$ is the Poisson's ratio for the material [a value of 0.25 was substituted for porcelain](26), $\mathrm{h}$ is the specimen thickness measured with the digital micrometer and $\ln$ is the natural logarithm.

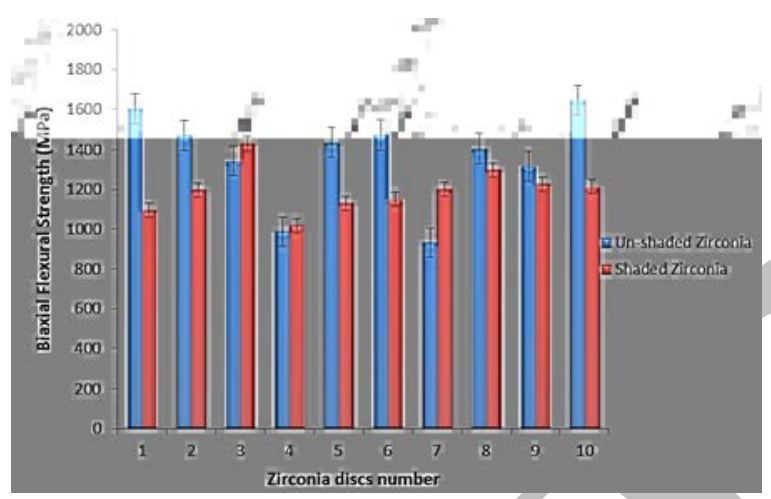

Figure 3: Biaxial Flexural strength test results of shaded and unshaded zirconia discs.

\section{Statistical analysis}

Statistical package of social sciences [SPSS v. 20] software was used for statistical analysis. Analysis of variance [ANOVA] was done to compare results of different groups. The level of statistical significance for all tests will be set at $\mathrm{P} \leq 0.05$.

\section{$\mathrm{X}$ - ray Diffraction (XRD)}

Zirconia discs fragments of both groups were crushed and ground in a ball mill for 6 hours. XRD analysis was done for both un-shaded and shaded zirconia powder samples using X-Ray Diffractometer (XRD-7000 ShimadzuJapan). Powder samples were packed in to a flat aluminum holder and scanned with $\mathrm{CuK} \alpha$ radiation $(\lambda=0.154060 \mathrm{~nm})$ generated at $30 \mathrm{KV}$ and $30 \mathrm{~nm}$. Scans were performed at $2^{\circ}$ min-1 for $2 \theta$ values between 10 and 90 degree. Crystalline phases were identified by comparison with the ICDD file (ZrO2: 37-64 (monoclinic phase), 17-0923 and 42-1164 (tetragonal phase).

\section{Confocal Laser microscopy}

Fractured surfaces of Fragments of one disc from each group were supported on glass slap using thin layer of white plasticine. Surfaces were then examined using confocal laser microscopy [VK-X100, Keyence Microscope Europe] at magnification 20X.

\section{RESULTS}

\section{Biaxial Flexural strength Test}

Biaxial flexural strength test of Un-shaded and shaded translucent monolithic zirconia discs are given in (Figure 3) showing that the BFS values of 7 un-shaded discs out of 10 were higher than that of shaded discs. However, the One-way ANOVA Statistical test revealed a statistically insignificant difference $(\mathrm{P}=0.06)$ in flexural strength between the two groups (Table 2).

Table 2:Statistical analysis of biaxial flexural strength test values of both groups using One-way ANOVA.

\begin{tabular}{|c|c|c|c|c|c|c|}
\hline \multicolumn{7}{|l|}{ SUMMARY } \\
\hline Groups & Count & Sum & $\begin{array}{l}\text { Aver } \\
\text { age }\end{array}$ & $\begin{array}{l}\text { Vari } \\
\text { ance }\end{array}$ & & \\
\hline $\begin{array}{l}\text { Un-shaded } \\
\text { Zirconia }\end{array}$ & 10 & $\begin{array}{l}13609.6 \\
4\end{array}$ & $\begin{array}{l}1360 \\
.964\end{array}$ & $\begin{array}{l}5512 \\
4.95\end{array}$ & & \\
\hline $\begin{array}{l}\text { Shaded } \\
\text { Zirconia }\end{array}$ & 10 & $\begin{array}{l}11958.8 \\
6\end{array}$ & $\begin{array}{l}1195 \\
.886\end{array}$ & $\begin{array}{l}1268 \\
3.86\end{array}$ & & \\
\hline \multicolumn{7}{|l|}{ ANOVA } \\
\hline $\begin{array}{l}\text { Source of } \\
\text { Variation }\end{array}$ & SS & $d f$ & MS & $F$ & $\begin{array}{l}P \text { - } \\
\text { value }\end{array}$ & $\begin{array}{l}F \\
\text { crit }\end{array}$ \\
\hline $\begin{array}{l}\text { Between } \\
\text { Groups }\end{array}$ & $\begin{array}{l}136253 . \\
7\end{array}$ & 1 & $\begin{array}{l}1362 \\
53.7\end{array}$ & $\begin{array}{l}4.01 \\
8762\end{array}$ & $\begin{array}{l}0.06 \\
0276\end{array}$ & $\begin{array}{l}4.41 \\
3873\end{array}$ \\
\hline $\begin{array}{l}\text { Within } \\
\text { Groups }\end{array}$ & $\begin{array}{l}610279 . \\
3\end{array}$ & 18 & $\begin{array}{l}3390 \\
4.41\end{array}$ & & & \\
\hline Total & $\begin{array}{l}746533 . \\
1\end{array}$ & 19 & & & & \\
\hline
\end{tabular}

$\mathrm{X}$-ray diffraction test results

All specimens analyzed using XRD showed only tetragonal $\mathrm{ZrO} 2$ phase characteristics peaks. None of the samples showed any tetragonal-monoclinic transformation or coloring oxides crystal phases (Figure 4).

\section{Confocal Laser microscopy}

Confocal laser microscopy images of fractured surfaces after the flexural strength test of both groups characteristic fractures patterns of mirror, mist, and hackle features surrounding the fracture origin (Figure 5 and 6).

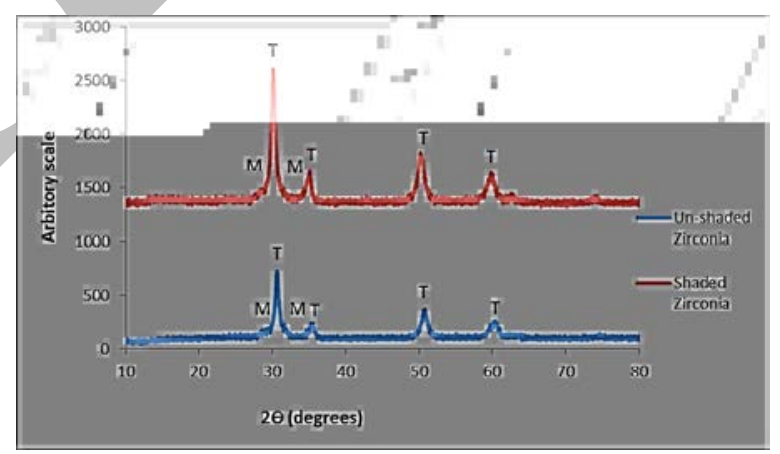

Figure 4: XRD spectrum of Shaded zirconia discs (T) tetragonal, (M) monoclinic zirconia phases.

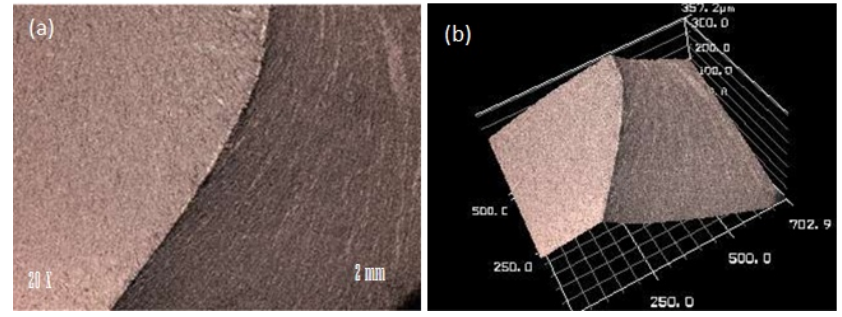

Figure 5: CLSM image for fracture Un-shaded zirconia disc (a) 20X image (b) 3D image showing Cone-shape fracture line, Hackles and Mirrors. 


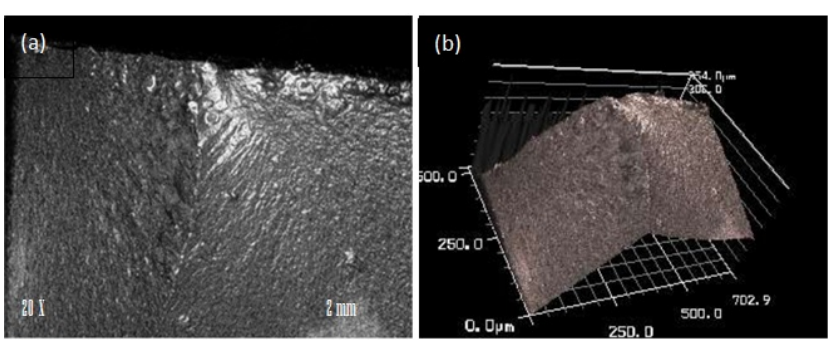

Figure 6: shows CLM image for fracture Un-shaded zirconia disc (a) 20X image (b) 3D image showing Cone-shape fracture line, Hackles and Mirrors.

\section{DISCUSSION}

BFS test results showed that the average BFS values were (1361 and $1196 \mathrm{MPa}$ for un-shaded and shaded commercial zirconia discs) (Table 2, Figure 3). These values were comparable with some BFS reports in the literature for monolithic zirconia. Schatz et al. tested the BFS of zirconia discs (Zenostar Zr Translucent) and the results of wet polished samples after sintering were (1139; $1202 \mathrm{MPa}$ ). BFS values of other commercial monolithic zirconia in Schatz study with the same test conditions also showed comparable values with ours (Ceramill Zolid, BFS=1090; 1152 MPa; DD Bio zx2, BFS=1346; 1472 $\mathrm{MPa}$ ) (27). However, BFS values were slightly higher than some BFS reports in the literature for other commercial monolithic zirconia (Bruxzir HT, BFS=906; $1000 \mathrm{MPa}$ ) (28), (NobelProcera, BFS $=856$ and $842 \mathrm{MPa}$ for unshaded and shaded materials) (22), (BruxZir Shaded 16, $\mathrm{FS}=921.7$; inCoris TZI C, FS=855.2; Lava Plus, $\mathrm{FS}=880.0$ ) (29). This difference in flexural strength values could not only be a result of using different commercial products, but it could also be a result of specimen preparation (wet polishing) after sintering. Same effect of specimen preparation after sintering on BFS of the same material used in this work was reported by Schatz et.al. The increase in flexural strength in Schatz 's study was attributed to the occurrence phase transformation form tetragonal to monoclinic after specimen preparation, which was associated with compressive surface stresses and thus elevate the flexural strength (27). Other studies also showed this increase in the amount of the monoclinic phase, when the surface was treated after sintering (30, 31). In contrast to that, in the present study no higher fraction of monoclinic zirconia on the surface of wet polished specimen was found in XRD results (Figure 4). Thus the polishing procedure must have removed the layer of monoclinic zirconia. However, it should be mentioned that in contrast to this assumption, other studies described a decrease in flexural strength of zirconia, when the surface underwent a grinding process $(32,33)$.

The null hypothesis was accepted as the statistical analysis of BFS test results (Table 2) showed that there was no statistically significant difference found between un-shaded and shaded samples $(\mathrm{P}=0.06)$. This result indicates that there was no effect of addition of coloring to the shaded composition before sintering on BFS of monolithic zirconia. This insignificant difference could be attributed to the low percentage of coloring oxides added during manufacturing of zirconia blanks (Table 1). Also XRD results (Figure 4), did not show the presence of any coloring oxide crystal phases as iron oxide for example, which could give an indication about its low percentage in shaded zirconia composition. Similar results were reported by Spyropoulou et al. using shaded (Powder mixing method) and un-shaded Nobel Procera (Nobel Biocare AB) monolithic zirconia (22). Also Pittayachawan et al. reported simillar insignificant difference (21). In contrast to what has been reported by Hjerppe et al. using higher concentration of coloring pigments (18) and Shah et al. using non Fe-O based coloring pigments (17). Characteristic XRD patterns for the Un-shaded and shaded zirconia presented in (Figures 3) showed that the peak positions of shaded zirconia samples were correspond to that of Un-shaded ones. The tetragonal phase was the main crystal structure in the XRD patterns of both groups. As mentioned before, the presence of additional metal oxides in shaded group was expected to modify the lattice parameters of 3Y-TZP. However, our results showed that only tetragonal phase was present. XRD patterns of both groups indicated that the samples had nearly the same crystal structure. Therefore, it could be clearly said that there was no negative effect of coloring oxide on tetragonal crystal phase formation. Nascente and de Souza's study (34) demonstrated that the addition of iron oxide to zirconia stabilized with ceria could help to stabilize the tetragonal phase. Similar XRD results of shaded zirconia were found by Tian et al. using Fe2O3 pigmented zirconia (35), Shah et al. (17) and Spyropoulou et al. (22). CLSM images of the fractured surfaces in both group specimens (Figure 5 and 6) showed the same classical fracture patterns of brittle (mirror, mist, and hackle surrounding the fracture origin) described by Quinn G. (36). Similar fracture patterns of monolithic translucent zirconia were reported before (37-39).

\section{CONCLUSION}

- Monolithic translucent zirconia shading using powder mixing method does not significantly affect biaxial flexural strength of the produced zirconia discs.

- Low percentage of coloring oxide $(\leq 1 \%)$ does not affect the crystallographic structure of monolithic translucent zirconia.

- Both Un-shaded and Shaded discs showed same fracture patterns under Confocal laser microscopy.

\section{CONFLICT OF INTEREST}

The authors declare that they have no conflicts of interest.

\section{REFERENCES}

1. Springate SD, Winchester LJ. An evaluation of zirconium oxide brackets: a preliminary laboratory and clinical report. Br J Orthod. 1991; 18(3):203-9.

2. Nothdurft FP, Pospiech PR. Clinical evaluation of pulpless teeth restored with conventionally cemented zirconia posts: a pilot study. J. Prosthet. Dent. 2006; 95(4):311-4.

3. Manicone PF, Iommetti PR, Raffaelli L. An overview of zirconia ceramics: basic properties and clinical applications. J Dent. 2007; 35(11):819-26.

4. Nakamura K, Kanno $T$, Milleding $P$, Örtengren U. Zirconia as a dental implant abutment material: a systematic review. Int J Prosthodont. 2010; 23(4).

5. Wenz HJ, Bartsch J, Wolfart S, Kern M. Osseointegration and clinical success of zirconia dental implants: a systematic review. Int J Prosthodont. 2008; 21(1). 
6. Raigrodski AJ. Contemporary materials and technologies for all-ceramic fixed partial dentures: a review of the literature. J Prosthet Dent. 2004; 92(6):557-62.

7. Lüthy H, Filser F, Loeffel O, Schumacher M, Gauckler LJ, Hammerle CH. Strength and reliability of four-unit allceramic posterior bridges. Dent Mater. 2005; 21(10):930-7.

8. Denry I, Kelly JR. State of the art of zirconia for dental applications. Dent Mater. 2008; 24(3):299-307.

9. Raigrodski AJ, Hillstead MB, Meng GK, Chung KH. Survival and complications of zirconia-based fixed dental prostheses: a systematic review. J Prosthet Dent. 2012; 107(3):170-7.

10. Beuer F, Stimmelmayr M, Gueth JF, Edelhoff D, Naumann M. In vitro performance of full-contour zirconia single crowns. Dent Mater. 2012; 28(4):449-56.

11. Johansson C, Kmet G, Rivera J, Larsson C, Vult Von Steyern P. Fracture strength of monolithic all-ceramic crowns made of high translucent yttrium oxide-stabilized zirconium dioxide compared to porcelain-veneered crowns and lithium disilicate crowns. Acta Odontol Scand. 2014; 72(2):145-53.

12. Garvie RC, Hannink RH, Pascoe RT. Ceramic steel?. Nature. 1975; 258(5537):703-4.

13. Kelly PM, Ball CJ. Crystallography of Stress-Induced Martensitic Transformations in Partially Stabilized Zirconia. J. Am. Ceram. Soc. 1986; 69(3):259-64.

14. Piconi C, Maccauro G. Zirconia as a ceramic biomaterial. Biomaterials. 1999; 20(1):1-25.

15. Chevalier J, Gremillard L, Deville S. Low-temperature degradation of zirconia and implications for biomedical implants. Annu. Rev. Mater. Res. 2007; 37:1-32.

16. Cales B. Colored zirconia ceramics for dental applications. InBIOCERAMICS-CONFERENCE.1998; 11:591-4.

17. Shah K, Holloway JA, Denry IL. Effect of coloring with various metal oxides on the microstructure, color, and flexural strength of 3Y-TZP. J Biomed Mater Res. 2008; 87(2):329-37.

18. Hjerppe J, Närhi T, Fröberg K, Vallittu PK, Lassila LV. Effect of shading the zirconia framework on biaxial strength and surface microhardness. Acta Odontol Scand. 2008; 66(5):262-7.

19. Kaya G. Production and characterization of self-colored dental zirconia blocks. CERAM INT. 2013 Jan; 39(1):511-7.

20. Kuroda S, Shinya A, Yokoyama D, Harunori GO, Shinya A. Effects of coloring agents applied during sintering on bending strength and hardness of zirconia ceramics. Dent Mater J. 2013; 32(5):793-800.

21. Pittayachawan P, McDonald A, Petrie A, Knowles JC. The biaxial flexural strength and fatigue property of LavaTM YTZP dental ceramic. Dent Mater. 2007; 23(8):1018-29.

22. Spyropoulou PE, Kamposiora P, Eliades G, Papavasiliou G, Razzoog ME, Thompson JY, Smith RL, Bayne SC. Composition, phase analysis, biaxial flexural strength, and fatigue of unshaded versus shaded Procera zirconia ceramic. J Prosthet Dent. 2016; 116(2):269-76.

23. Gale MS, Darvell BW. Thermal cycling procedures for laboratory testing of dental restorations. J Dent. 1999; 27(2):89-99.

24. Bhamra G, Palin WM, Fleming GJ. The effect of surface roughness on the flexure strength of an alumina reinforced all-ceramic crown material. J Dent. 2002; 30(4):153-60. 25. Timoshenko SP, Woinowsky-Krieger S. Theory of plates and shells. McGraw-hill; 1959.
26. Anusavice KJ, Dehoff PH, Fairhurst CW. Materials Science: Comparative Evaluation of Ceramic-metal Bond Tests Using Finite Element Stress Analysis. J Dent Res. 1980; 59(3):608-13.

27. Schatz C, Strickstrock M, Roos M, Edelhoff D, Eichberger M, Zylla IM, Stawarczyk B. Influence of specimen preparation and test methods on the flexural strength results of monolithic zirconia materials. Materials. 2016; 9(3):180.

28. Ebeid K, Wille S, Hamdy A, Salah T, El-Etreby A, Kern M. Effect of changes in sintering parameters on monolithic translucent zirconia. Dent Mater. 2014 Dec 31;30(12):e419-24.

29. Church TD, Jessup JP, Guillory VL, Vandewalle KS. Translucency and strength of high-translucency monolithic zirconium oxide materials. Gen Dent. 2017; 65(1):48-52.

30. Karakoca S, Yilmaz H. Influence of surface treatments on surface roughness, phase transformation, and biaxial flexural strength of Y-TZP ceramics. J Biomed Mater Res. 2009; 91(2):930-37.

31. Kosmač T, Oblak C, Jevnikar P, Funduk N, Marion L. The effect of surface grinding and sandblasting on flexural strength and reliability of Y-TZP zirconia ceramic. Dent Mater. 1999; 15(6):426-33.

32. Curtis AR, Wright AJ, Fleming GJ. The influence of surface modification techniques on the performance of a Y-TZP dental ceramic. J Dent. 2006; 34(3):195-206.

33. Luthardt RG, Holzhüter M, Sandkuhl O, Herold V, Schnapp JD, Kuhlisch E, Walter M. Reliability and properties of ground Y-TZP-zirconia ceramics. J Dent Res. 2002; 81(7):487-91.

34. Nascente PA, de Souza DP. XPS characterisation of ceria-stabilised zirconia doped with iron oxide. Appl. Surf. Sci. 1999; 144:228-32.

35. Wen N, Yi YF, Zhang WW, Deng B, Shao LQ, Dong LM, Tian JM. The color of Fe2O3 and $\mathrm{Bi} 2 \mathrm{O} 3$ pigmented dental zirconia ceramic. InKey Engineering Materials. Trans Tech Publications .2010; 434:582-5.

36. Quinn GD. Fractography of ceramics and glasses. Washington, DC: National Institute of Standards and Technology; 2007.

37. Lameira DP, De Souza GM. Fracture strength of aged monolithic and bilayer zirconia-based crowns. BioMed Res. Int. 2015.

38. Nakamura K, Mouhat M, Nergård JM, Lægreid SJ, Kanno T, Milleding P, Örtengren U. Effect of cements on fracture resistance of monolithic zirconia crowns. Acta Odontol Scand. 2016; 2(1):12-9.

39. Øilo M, Kvam K, Gjerdet NR. Load at fracture of monolithic and bilayered zirconia crowns with and without a cervical zirconia collar. J Prosthet Dent. 2016; 115(5):630-6. 